Pecvnia, 7 (2008), pp. 207-226

\title{
El principio de igualdad y la no discriminación del trabajador autónomo en el ordenamiento jurídico español ${ }^{1}$
}

Recibido: Octubre 2008

Aceptado: Mayo 2009

\author{
$M^{a}$ de los Reyes Martínez Barroso \\ mrmarb@unileon.es \\ Universidad de León \\ Fac. de Ciencias del Trabajo \\ Campus de Vegazana, $\mathrm{s} / \mathrm{n}$ \\ 24071 León (España)
}

Dentro del capítulo dedicado a regular el régimen profesional común del trabajador autónomo, el reciente Estatuto del Trabajo Autónomo, aprobado por Ley 20/2007, de 11 de julio dedica una atención especial al principio de igualdad y no discriminación. En las páginas que siguen se analizan exhaustivamente las consecuencias de tal reconocimiento expreso así como la protección antidiscriminatoria y las medidas que deben adoptar los poderes públicos para la tutela de tal derecho fundamental, sin
Inside the chapter dedicated to regulate the professional common regime of the autonomous worker, the recent Statute of the Autonomous Work, approved by Law 20/2007, of 11 of July, he dedicates a special attention initially of equality and not discrimination. In the pages that continue there are analyzed exhaustively the consequences of such an express recognition as well as the antidiscriminatory protection and the measures that must adopt the public power for the guardianship of such a

Comunicación presentada al IX Congreso Europeo de Derecho del Trabajo y de la Seguridad Social, 16-19 septiembre de 2008, Friburgo, Alemania. 
olvidar la especial relevancia que presenta el derecho a no ser discriminado por razones de discapacidad, con referencia expresa a la Ley $51 / 2003$, de igualdad de oportunidades, no discriminación y accesibilidad universal, poniendo de relieve cómo en el caso de los autónomos el derecho genérico a la no discriminación y la remisión específica resultan a todas luces insuficientes, siendo necesarios los instrumentos de aplicación ya existentes para los trabajadores por cuenta ajena.

Palabras clave: Igualdad, no discriminación, autónomo, TRADE, autónomo discapacitado. fundamental right, without forgetting the special relevancy that presents the right not to be discriminated for reasons of disability, with reference it expresses to the Law 51/2003, of equality of opportunities, not discrimination and universal accessibility, emphasizing how in case of the autonomous ones the generic right to not discrimination and the specific reference prove to all insufficient lights, belonging necessary the already existing instruments of application for the workers for foreign account.

Key words: Equality, not discrimination, autonomous, TRADE, autonomous disabled person.

\section{INTRODUCCIÓN}

La normativa laboral representa una de las vías esenciales a través de las cuales los poderes públicos han cumplido el mandato constitucional de promover los valores de igualdad, libertad y dignidad de la persona. En la medida en que se va avanzando en el Estado social y democrático de derecho, las expectativas de profundización y extensión de dichos valores a cada vez más amplios sectores de la población es una aspiración lógica que demuestra el grado de salud y madurez de una sociedad. No extraña por ello, como no podía ser de otra forma, que el reciente Estatuto del Trabajo Autónomo (LETA), aprobado en España por Ley 20/2007, de 11 de julio, incorpore un Capítulo dedicado a regular el régimen profesional común del trabajador autónomo, a través de un amplio catálogo de derechos y deberes profesionales básicos "en el ejercicio de su actividad profesional", poniendo fin con ello -al menos de un modo teórico o programático- a lo que algunos han calificado de "déficit democrático" injustificable con respecto a este colectivo².

Entre ellos, como derecho subjetivo de la persona, el art. 4.3 LETA reconoce expresamente a los autónomos el derecho a la igualdad ante la ley y a no ser discriminado por ninguna condición o circunstancia personal o social, incluida la discapacidad, otorgándole una

2 UPTA (2005) "Posición de la UPTA sobre el Estatuto del Trabajo Autónomo", Documentación Laboral, 73, p. 137. 
protección especial en coherencia con el reforzamiento de este derecho a partir de la renovación del ordenamiento comunitario.

\section{EL PRINCIPIO DE IGUALDAD EN EL SENO DE UN CATÁLOGO LEGAL DE DERECHOS PARA EL TRABAJADOR AUTÓNOMO}

Una parte sustancial de ese régimen común es la dedicada al estatuto de derechos, deberes y garantías del trabajador autónomo, sin perjuicio de algún precepto de contenido muy singular (como el referido a la forma y duración del contrato). El bloque primero y fundamental es el dedicado a la consagración de los denominados "derechos profesionales", que en realidad se compone de derechos de muy distinto signo, algunos de ellos de carácter personal o de ciudadanía más que de carácter profesional.

El tratamiento unitario para los autónomos ordinarios y para los trabajadores autónomos económicamente dependientes (TRADE) de los mismos derechos y deberes es posible a partir de la aspiración de la LETA de ser una norma marco, de carácter "estatutario", antes que una Ley llamada a regular con detalle el régimen legal de estos trabajadores pero como contrapartida exige unas pautas de generalidad $y$, consecuentemente, de no poca indefinición. Tratar aunadamente los derechos de unos y de otros lleva necesariamente a adoptar un escenario intermedio que obliga a una necesaria remisión a la normativa constitucional y especial de desarrollo, perdiendo por ello utilidad la enunciación del catálogo de derechos ${ }^{3}$.

Esa tarea de listar los derechos básicos que integran este Estatuto común la realiza el art. 4 LETA, cuya estructura dual recibe la inspiración directa de su homólogo art. 4 del Estatuto de los Trabajadores (LET), con el propósito de extender al mundo del trabajo autónomo derechos que a menudo se acotan o restringen, legal o judicialmente, a los trabajadores asalariados, en especial, cuando tienen un fundamento constitucional. En unos casos, la sola incorporación dentro del catálogo constituiría un instrumento útil a los efectos de dejar constancia de que

E. González Biedma (2007) "Derechos y deberes de los trabajadores autónomos". S. del Rey Guanter (dir.) Comentarios al Estatuto del Trabajo Autónomo. Valladolid: Lex Nova, p. 117. 
en tales casos la titularidad es común para los trabajadores. En otros, se plantea como una "enumeración de avance", de modo que su desarrollo legal se produce en preceptos sucesivos de la Ley, donde se pretende perfilar con el suficiente detalle su concreto régimen jurídico. El problema será determinar, en aquellos casos en que el enunciado del derecho no va acompañado de un régimen coherente, si tienen o no una vigencia directa que, desde luego, no queda asegurada con el solo reconocimiento, aunque debe servir de orientación interpretativa ${ }^{4}$.

Primeramente se les atribuyen los derechos fundamentales y libertades públicas reconocidos en la CE y Tratados Internacionales, reconociendo de este modo la eficacia entre particulares de tales derechos y remitiendo a una copiosa regulación legal y actividad judicial. La declaración, en realidad, no era necesaria pues va de suyo que los trabajadores autónomos son también ciudadanos y titulares de los derechos correspondientes. Es además una declaración que puede inducir a confusión, pues dentro de esa sección constitucional hay derechos muy variados, sobre los que cabría preguntarse si pueden ser ejercitados por los autónomos en cuanto tales, o si tiene algún sentido reconocerlos a estos efectos. Los derechos de más pura ciudadanía, como el de participación en asuntos públicos, el de acceso a los cargos públicos o el de educación (arts 23 y $27 \mathrm{CE}$ ) no es que no pertenezcan al trabajador autónomo como persona, sino que, sencillamente, no tienen nada que ver con el trabajo autónomo y con el acceso a esa fuente de ingresos o con la realización de la correspondiente actividad.

Una vez realizada tal solemne declaración, el art. 4 LETA hace una distinción puramente formal entre derechos "básicos" y derechos "en el ejercicio de su actividad profesional", que en realidad no tiene mayor sentido ni justificación, pues no se entiende bien, por ejemplo, que no se incluyan entre los de carácter básico los derechos a la igualdad o a la intimidad, o que no se conecten al ejercicio de la actividad los derechos de propiedad intelectual, o incluso de libertad de profesión y

J. Fernández-Costales Muñiz (2008) "Aproximación de la figura del trabajador autónomo y su régimen profesional común en la Ley 20/2007, de 11 de julio, del estatuto del trabajo autónomo", Revista Técnico Laboral, 115, pp. 80-81. 
oficio, sin olvidar además que dicho precepto comprende tan sólo derechos individuales, dejando los colectivos para un capítulo distinto ${ }^{5}$.

A renglón seguido se enumeran los doctrinalmente denominados "derechos económicos": derecho individual al trabajo y a la libre elección de profesión u oficio; a la libertad de iniciativa económica y libre competencia y a la propiedad intelectual sobre sus obras o prestaciones. Esto es, no sólo se protege la cualidad de sujeto económico puesto en acción por quien presta servicios socialmente útiles, sino la típica de "empresario", de ahí que aparezcan derechos que habitualmente no aparecen en el catálogo fijado para los trabajadores subordinados como ocurre con la libertad de iniciativa económica y el derecho a la libre competencia. Ambos reflejan el derecho constitucional a la libertad de empresa del titular de la iniciativa económica -emprendedor-y de los medios de producción necesarios para llevarla a cabo. El derecho a la libre competencia protege la faceta empresarial del autónomo favoreciendo su presencia en el mercado y prohibiendo la creación de obstáculos que dificulten o impidan su concurrencia y se revela como una de las materias más conflictivas del Estatuto profesional en la medida en que la libertad de competencia no es solo un derecho del trabajador autónomo sino también un "deber", como prueban las diversas referencias que se hacen a este límite en el art. 13 LETA, en relación con los acuerdos de interés profesional $^{6}$, pero también en relación a la eventual fijación de tiempos de trabajo o dedicación, como ilustra la vicisitud de esta materia en la ordenación comunitaria. Por último, es evidente el mayor alcance que en este ámbito de relaciones contractuales tiene la regulación de la propiedad intelectual, una vez más por la propia consideración del trabajador autónomo como un trabajador por cuenta propia que ha de gestionar la utilidad económica de sus obras y servicios en el mercado. La dimensión empresarial y creadora del trabajador autónomo es conceptualmente superior a la del asalariado.

5 J. García Murcia (2007) "Trabajo autónomo". J. García Murcia (dir.) El trabajo autónomo y otras formas de trabajo no asalariado. Cizur Menor: Thomson-Aranzadi, pp. 46-47.

6 La LETA es consciente, de alguna forma, de que existe un conflicto entre la libre competencia y los acuerdos de interés profesional, saliendo al paso, por ejemplo, a través de una alusión de indudable relevancia pero escasa, por cuanto que no fija reglas concretas para dirimir el conflicto, aunque sí lo divisa. Es el caso, por ejemplo, del art. 17.2 de la LETA cuando dispone que la Jurisdicción Social es competente para conocer de las cuestiones derivadas de la aplicación e interpretación de aquellos acuerdos "... sin perjuicio de lo dispuesto en la legislación de defensa de la competencia". Sobre el particular, M.L. Segoviano Astaburuaga (2007) "Trabajadores autónomos económicamente dependientes", Documentación Laboral, 81, p. 38. 
Con posterioridad se listan una serie de derechos "profesionales": igualdad ante la ley y no discriminación; formación y readaptación profesionales; integridad física y protección adecuada de su seguridad y salud en el trabajo; percepción "puntual" de la contraprestación económica convenida por el ejercicio profesional de su actividad-cabe entender, en el tiempo y forma establecidos, formulando el principio de pacta sunt servandae-; conciliación de su actividad profesional con sus responsabilidades familiares; respeto de su intimidad y consideración debida a su dignidad, así como a una "adecuada protección" frente al acoso sexual y por razón de sexo o por cualquier otra circunstancia o condición personal o social; asistencia y prestaciones sociales suficientes ante situaciones de necesidad, de conformidad con la legislación de Seguridad Social y derechos procesales: acceso a los medios extrajudiciales de solución de conflictos - de momento meramente programático en la medida en que no se han llegado a materializar de manera específica para los trabajadores autónomos, si bien podría llegarse a unos "macro-acuerdos", sobre la base de afiliación que supongan las asociaciones profesionales o sindicales que engloben a los TRADE para alcanzar estas vías alternativas de solución de conflictos ${ }^{7}-\mathrm{y}$ a la tutela judicial efectiva de sus derechos profesionales.

Como puede apreciarse, son derechos muy variados tanto en su configuración como en su virtualidad o manera de operar, pues mientras algunos tiene vigencia por sí mismos (como la igualdad, la intimidad o la tutela judicial efectiva) otros requieren una legislación de apoyo para su ejercicio (formación profesional, seguridad $\mathrm{y}$ salud en el trabajo, conciliación de la vida laboral y familiar o protección social), o, en fin, la puesta en marcha de los servicios pertinentes, como el derecho a utilizar medios extrajudiciales de solución de conflictos. Además, el destinatario de esos derechos, en su condición de parte obligada a respetarlos, puede quedar en el terreno de la "indefinición", pues el autónomo, salvo excepciones, no mantiene exactamente una relación de trabajo en la que esos derechos debieran ser observados o estuvieran en peligro, sino únicamente una relación con el cliente o con la Administración pública;

Con carácter general N. Sirvent Hernández (2007) "Los acuerdos de interés profesional como fuente reguladora de la relación profesional de los trabajadores autónomos económicamente dependientes", Revista de Trabajo y Seguridad Social, 296, p. 49 y ss. o M.R. Martínez Barroso (2008) "La concertación de acuerdos de interés profesional", Diario La Ley, 7082, pp. $1-9$. 
esto es, derechos que pueden tener sentido en el caso de quienes mantengan con una empresa una relación estable o de cierta continuidad, pero que para el autónomo por excelencia añade muy poco a lo que ya tiene atribuido como persona por el texto constitucional ${ }^{8}$.

Efectivamente, se trata de prerrogativas recogidas en su mayor parte en la Constitución Española para todos los ciudadanos por el mero hecho de serlo y que, sin embargo, no solamente no se habían reconocido expresamente para los autónomos sino que, al contrario, han sido objeto de interpretación y aplicación restrictiva a los mismos, en ocasiones a nivel jurisprudencial y otras veces directamente por las leyes de desarrollo de la Carta Magna. Sin embargo, han de resultar "de directa aplicación al colectivo", porque muchos de ellos son derechos fundamentales y por tanto "tienen eficacia horizontal de directa aplicación a los derechos laborales... que no se refieren exclusivamente al trabajo por cuenta ajena o dependiente sino al trabajo en su conjunto, entendido como actividad social productiva"'. Dado que la reserva constitucional a la ley orgánica comprende, exclusivamente, las ordenaciones jurídicas directas y completas de los derechos fundamentales, la ley ordinaria puede entrar a disciplinar aspectos que resulten bien conexos o indirectos bien complementarios o accesorios. Así delimitado el sentido del art. 81.1 CE, el tratamiento normativo que la LETA lleva a cabo de determinados derechos fundamentales relacionados con el ejercicio, por parte de trabajadores autónomos, de su actividad profesional supera con holgura este canon de interpretación constitucional.

Ninguna disposición de la Ley 20/2007 entra en el desarrollo de un derecho fundamental ni de manera directa o frontal ni con la pretensión de suministrar una regulación completa y suficiente del derecho en cuestión. Por el contrario, contiene referencias a los derechos que regula de alcance o bien muy general o bien muy secundario. Buenos ejemplos de la primera forma de desarrollo normativo lo ofrecen los arts. 4.3. a), c), y j), 19.1.a) y 19.2.a) de la ley comentada, preceptos éstos que se limitan, sin más concreciones, a reconocer a los trabajadores autónomos la titularidad de los derechos a la igualdad y no discriminación (art. $14 \mathrm{CE}$ ), a la intimidad y consideración debida a su dignidad como

\footnotetext{
J. García Murcia (2007) "Trabajo autónomo", ed. cit., p. 48.

UPTA (2005) "Posición de la UPTA sobre el Estatuto del Trabajo Autónomo",

ed. cit., p. 137.
} 
persona (art. 18.1 CE), a la tutela judicial efectiva (art. 24.1), a afiliarse al sindicato de su elección (art. 28.1 CE) y asociarse a la organización de su elección (art. $20 \mathrm{CE}$ ) o, en fin, a constituir federaciones y confederaciones por parte de uno y otra (arts. 10 y $28.1 \mathrm{CE}$ ). Por su parte, una buena ilustración del sentido de las regulaciones indirectas, accesorias e incompletas lo suministra el art. 20 LETA, cuando establece determinadas especialidades o particularidades del derecho de asociación de los trabajadores autónomos atendiendo bien a su composición subjetiva y a los objetivos que las mismas procuran satisfacer (art. 20.2) bien a la naturaleza del órgano administrativo encargado de adoptar medidas de promoción del autoempleo (art. 20.3). Por lo demás, el carácter incompleto o accesorio de las regulaciones de la LETA en materia de derechos fundamentales se desprende de las remisiones que la propia ley ordinaria hace a las respectivas leyes orgánicas, bien genéricamente a su totalidad ${ }^{10}$ bien de manera singularizada a un concreto precepto ${ }^{11}$.

De todos ellos, el derecho más incisivo en cuanto al respeto de los intereses personales del trabajador en relación con el ejercicio de su actividad profesional es el relativo a la protección de la intimidad, con el mismo enunciado que el establecido para su homólogo art. 4.2 e) LET, en la redacción dada por las diferentes reformas del mismo - Ley 62/2003 y LO 3/2007-, que a su vez constituyen la versión laboral de los derechos constitucionales recogidos en los arts. 10 y $18 \mathrm{CE}$. Como desarrollo de este precepto constitucional (art. $18 \mathrm{CE}$ ) se dictó la LO 1/1982, de 5 de mayo, de protección civil del derecho al honor, a la intimidad personal y familiar y a la propia imagen, y la LO 15/1999, de 13 de diciembre de Protección de Datos de Carácter Personal. La LETA lo plasma estableciendo que los trabajadores autónomos tienen derecho al respeto a su intimidad y a la consideración debida a su dignidad, así como a una adecuada protección frente al acoso sexual y al acoso por razón de sexo o por cualquier otra circunstancia o condición personal o social -art. 4.3 b)-. Esto es, el derecho a la intimidad de la persona también implica la prohibición de todas aquellas conductas que creen un entorno ofensivo o

10 Vid. arts. $1.4,6.5$ y 20.1 , que reenvían, respectivamente, a las Leyes orgánicas 4/2000, de 11 de enero, de derechos y libertades de los extranjeros en España y su integración social; $3 / 2007$, de 22 de marzo, para la igualdad efectiva de hombres y mujeres y $1 / 2002$, de 22 de marzo, reguladora del derecho de asociación. Laboral, 81, pp. 16-17.

1 F. Valdés Dal-Re (2007) "Un Estatuto para el trabajo autónomo", Documentación 
humillante para el trabajador ${ }^{12}$. Pero sin ningún género de duda lo más novedoso, no tanto respecto de la vigencia del art. 14 CE sino de la normativa comunitaria y de la legislación nacional que la ha transpuesto, es la inclusión en este ámbito de una protección específica no ya solo respecto del acoso sexual, definido en el art. 7.1 LO 3/2007 y acotado por la doctrina constitucional, sino la prohibición del "acoso discriminatorio" en general, por cuanto hasta el momento el acoso discriminatorio se vinculaba a motivos concretos de trato peyorativo y no conforme a una fórmula amplia ${ }^{13}$. En la LETA el acoso ${ }^{14}$, el mobbing, queda explícitamente prohibido, de manera directa y expresa, cualquiera que sea la causa que lo motiva, es decir, cuando se base en cualquier "circunstancia personal o social", constituyendo, por tanto, la primera norma que en el ordenamiento interno prohíbe radicalmente el acoso moral en todas sus dimensiones y por cualquier causa.

3. EL DERECHO A LA IGUALDAD ANTE LA LEY Y A NO SER DISCRIMINADO POR NINGUNA CONDICIÓN O CIRCUNSTANCIA PERSONAL O SOCIAL DEL TRABAJADOR AUTÓNOMO

La mención del art. 4.3 LETA se hace al derecho a "la igualdad ante la ley" como derecho distinto al de no discriminación pues, como es sabido, el primero significa precisamente eso, igualdad "ante la ley", en su vertiente de "en la propia ley" y en la aplicación e interpretación de la misma de manera que no es permisible ni concebir una ley ni ampliarla ni interpretarla con privilegio alguno. Ante la ley, el derecho a la igualad es pleno, si bien se admiten desigualdades cuando son justificadas y en la medida en que sean razonables y proporcionadas. Por el contrario, el derecho a la no discriminación se ejerce y disfruta no ante la ley sin ante todos los ciudadanos e instituciones, si bien la interdicción de discriminación sólo es predicable respecto de las causas específicas mencionadas en la norma que prohíbe la discriminación. Ello no obstante, la alusión

12 G. Barrios Baudor y M. Apilluelo Martín (2007) Introducción al Estatuto del Trabajo Autónomo. Cizur Menor: Thomson-Aranzadi, p. 70.

13 C. Molina Navarrete (2007) "Trabajadores en la frontera: Comentarios al Estatuto del Trabajo Autónomo", Revista de Trabajo y Seguridad Social, 295, pp. 78-79.

14 Me remito en esta materia a mi reciente monografía (2007) Riesgo psicosocial en el sistema de protección social. Murcia: Laborum y al amplio elenco de bibliografía allí recopilada. 
constitucional - ex art. 14- a la prohibición de toda discriminación también por "... otra condición o circunstancia personal o social" ha permitido a los tribunales, en no pocas ocasiones, aumentar el marco de las causas de interdicción de discriminación.

Con anterioridad a este reconocimiento expreso, algún sector especialmente crítico había considerado que cuando la Constitución Española reconoce la igualdad de todos los ciudadanos ante la Ley, la situación de los trabajadores autónomos "resulta incomprensiblemente discriminatoria y poco acorde con la deuda social que el conjunto de nuestra comunidad tiene respecto de quienes más arriesgan y se esfuerzan"15. La prohibición de discriminación afecta tanto a los poderes públicos como a quienes contraten la actividad profesional de los trabajadores autónomos y se extiende tanto a la libre iniciativa económica y a la contratación como a las condiciones de ejercicio profesional.

A la prohibición de discriminación -tanto directa como indirecta- y a la garantía de la efectividad de los derechos fundamentales y libertades públicas del trabajador autónomo dedica el Estatuto una especial atención (art. 6), pues lo más relevante de un régimen profesional no es tanto el reconocimiento de los derechos que integran la posición jurídica - garantía primaria- sino más bien los instrumentos de protección para hacerlos efectivos -garantías secundarias-. En consecuencia el precepto profundiza no ya sólo en el reconocimiento del derecho a la no discriminación sino también en la protección antidiscriminatoria y en las medidas que deben adoptar los poderes públicos para la tutela de los derechos fundamentales, sin olvidar la aplicación al trabajador autónomo de las exigencias derivadas de la Ley de Igualdad - Ley Orgánica 3/2007-. Y la medida encuentra justificación, además, en el acervo comunitario, pues como señala la Directiva 2006/54/CE, de 5 de julio, los Estados deben velar porque existan procedimientos judiciales para exigir el cumplimiento de las obligaciones establecidas con arreglo a la mencionada Directiva a favor de toda persona que se considere perjudicada por la no aplicación, en lo que a ella se refiera, del principio de igualdad de trato, incluso tras la terminación de la relación en la que supuestamente se haya producido la discriminación.

15 "Una normativa que ampare y proteja debidamente al trabajador autónomo no sólo es un acto de justicia sino una manera de fomentar la creación de riqueza y disminuir las listas de solicitantes de empleo". J.A. Durán i Lleida (2005) "La debida protección de los autónomos, una necesidad urgente", Revista de economía pública, social y cooperativa, 52, p. 27. 
Hasta ahora se han planteado pocas demandas por violación de estos derechos fundamentales y libertades públicas entre los autónomos por lo que puede mantenerse, más que la ausencia de estos comportamientos, que estas situaciones raramente llegan a los Tribunales y una de las razones de esta "renuncia judicial"16 del trabajador autónomo se ha basado precisamente en la inexistencia de un procedimiento judicial especial que ofreciera una respuesta a la incorporación de un procedimiento sumario y preferente en los términos exigidos por el art. 53.2 CE.

Con la redacción del art. 6.3 LETA finaliza la carencia expresada con anterioridad, pues los "poderes públicos deben garantizar la efectividad de los derechos fundamentales y libertades públicas del trabajador autónomo", esto es, la titularidad pasiva de estos derechos corresponde en exclusiva a los "poderes públicos", confortando así la tesis, preferida en el Derecho Privado "común" -y a diferencia de la posición del Derecho del Trabajo actual-, de la eficacia horizontal indirecta de los derechos fundamentales. Ahora bien, como con acierto interpreta la mejor doctrina, entre los poderes públicos concernidos también está el Juez, a quien corresponde la competencia no sólo de interpretar el ordenamiento, a través de una aplicación de las normas que regulan las relaciones de trabajo autónomo y control del ejercicio de las facultades del contrato, sino también de integración de su contenido mismo mediante la aplicación de cláusulas generales del Derecho privado, pero también directamente de los derechos reconocidos en el art. 4 LETA $^{17}$.

Los problemas de mayor alcance práctico y de más difícil solución son los planteados respecto a la incidencia de los derechos fundamentales en el control, sobre todo judicial, de las reglas introducidas por la autonomía de la voluntad. Esto es, en qué medida los derechos fundamentales no sólo actúan como límites a la autonomía privada, exigiendo una intervención protectora por parte de los poderes públicos, en especial del Juez, corrigiendo los excesos, sino también como fuentes de integración de la relación contractual. Para la prohibición de discriminación, en cambio, la LETA ha sido clara a la hora de afirmar la

16 F.A. González Díaz (2007) "Régimen profesional del trabajador autónomo". J. Luján Alcaraz (dir.) El Estatuto del Trabajo Autónomo. Análisis de la ley 20/2007, de 11 de julio. Murcia: Laborum, p. 76.

17 C. Molina Navarrete (2007) "Trabajadores en la frontera: Comentarios al Estatuto del Trabajo Autónomo", Revista de Trabajo y Seguridad Social, 295, pp. 84-86. 
eficacia directa en las relaciones contractuales de la prohibición de discriminar y, en consecuencia, se reconoce la cualidad de sujetos titulares pasivos u obligados tanto a los poderes públicos como a los particulares que contraten la actividad de los trabajadores autónomos (art. 6.2 LETA).

Como razones específicas de interdicción de discriminación se mencionan el nacimiento, origen racial o étnico, sexo, estado civil, religión, "convicciones", discapacidad, edad, orientación sexual y uso "de alguna de las lenguas oficiales dentro de España", además de cualquier otra condición personal o social. Estas razones se corresponden de manera casi literal con las actualmente expresadas en el art. 17 de la Ley del Estatuto de los Trabajadores (LET), siendo destacable la diferencia existente en la mención a la discriminación por razón de lengua, que utiliza una dicción más explícita y contundente en el art. 4.3.a) LETA, incidiendo en la polémica política lingüística en las comunidades autónomas con lengua propia y sugiriendo la controvertida cuestión de si resulta discriminatorio exigir a los trabajadores -autónomos en este caso- el conocimiento de ambas lenguas co-oficiales para la obtención de un determinado contrato o para no verlo extinguido.

El principio de igualdad de trato entre mujeres y hombres supone la ausencia de toda discriminación, directa o indirecta, por razón de sexo y, especialmente, las derivadas de la maternidad, asunción de obligaciones familiares y estado civil (art. 3 LOI). Como principio informador del ordenamiento jurídico se integrará y observará en la interpretación y aplicación de las normas jurídicas, en consecuencia, resulta aplicable en el ámbito del empleo tanto público como privado y se garantizará, en los términos previstos en la normativa aplicable, en el acceso al empleo, incluso al trabajo por cuenta propia, en la promoción y formación profesional $y$, entre otros aspectos, en las condiciones de trabajo (art. 5 LOI).

Como muy bien ha sintetizado la mejor doctrina, es discriminación directa por razón de sexo la situación en que se encuentra una persona que sea, haya sido o pudiera ser tratada en atención a su sexo, de manera menos favorable que otra en situación comparable; y se considera discriminatoria indirectamente aquella disposición, criterio o práctica aparentemente neutros que pone a personas de un sexo en desventaja particular con respecto a personas del otro, salvo que dicha 
disposición, criterio o práctica puedan justificarse objetivamente en atención a una finalidad legítima y que los medios para alcanzar dicha finalidad sean necesarios y adecuados ${ }^{18}$.

\section{DISCAPACIDAD}

\section{EN ESPECIAL, LA NO DISCRIMINACIÓN POR RAZÓN DE}

Desde hace más de dos décadas el legislador ha implementado una serie de medidas presididas por el afán de hacer efectiva la igualdad de este vulnerable colectivo ${ }^{19}$, si bien a pesar de todas esas medidas resalta una realidad incontestable cual es su elevada tasa de desempleo ${ }^{20}$. Y la razón no es otra que el inevitable conflicto entre dos bienes jurídicos protegidos constitucionalmente; el derecho de todos los ciudadanos al trabajo y, en especial respecto a los discapacitados, al derecho a la igualdad y la libertad de empresa y el derecho consiguiente del empresario a optimizar su inversión de capital a través del máximo beneficio de todos sus recursos, entre ellos, el trabajo que aportan los trabajadores contratados ${ }^{21}$.

De especial relevancia resulta, por tanto, la mención al derecho a no ser discriminado por razones de discapacidad del trabajador autónomo, con referencia expresa a la Ley 51/2003, de igualdad de oportunidades, no discriminación y accesibilidad universal, si bien en el caso de los autónomos el derecho genérico a la no discriminación y la remisión específica resultan a todas las luces insuficientes, siendo necesarios los instrumentos de aplicación ya existentes para los trabajadores por

18 G. Barrios Baudor y M. Apilluelo Martín (2007) Introducción al Estatuto del Trabajo Autónomo, ed. cit., p. 67.

19 Dado que el colectivo de trabajadores con discapacidad se encuentra en una clara situación de partida desventajosa respecto del resto de los aspirantes a un empleo, es necesario introducir medidas que faciliten o impongan la elección de tales trabajadores. G. Canals Sans (2003) "La inserción de personas con discapacidad en la empresa ordinaria", Documentación Social, 130, pp. 229-248.

20 Del conjunto de personas que en la actualidad en España padecen alguna discapacidad (3,5 millones), sólo el $24 \%$ accede a un empleo remunerado. Vid. IOE.: La inserción laboral de las personas con discapacidades, Estudios La Caixa, núm. 14 ó L. Cachón Rodríguez (dir.) (2004) Colectivos desfavorecidos en el mercado de trabajo y políticas activas de empleo. Madrid: MTAS, p. 109 y ss.

J. Escribano Gutiérrez (2008) "Igualdad y acceso al empleo de las personas con discapacidad", Revista Española de Derecho del Trabajo, 138, p. 405. 
cuenta ajena. Estos disponen de una serie de medidas dirigidas a potenciar la no discriminación en el acceso al empleo de los discapacitados, como son la exigencia de cuotas de trabajadores discapacitados en las empresas medianas y grandes, al margen de bonificaciones y subvenciones en sus contratos de trabajo o de instituciones específicas orientadas a su integración laboral, como los Centros Especiales de Empleo, los enclaves laborales y los programas de empleo con apoyo. Los mecanismos anteriormente mencionados son un mero apunte ejemplificativo del más amplio catálogo existente, susceptible de ser clasificado en dos macro grupos. Por un lado, las medidas que, con carácter general, exigen un trato de favor, traducido en ciertos porcentajes, de aquellos que por sus circunstancias personales están en una situación menos favorecida para su incorporación al mercado de trabajo; y, por otro, la proliferación de medidas incentivadoras en el marco de las medidas de fomento del empleo que periódicamente son publicadas en el $\mathrm{BOE}^{22}$.

En el caso de los autónomos queda, por el contrario, como acertadamente destaca la doctrina, todo ese camino por recorrer: establecimiento de ayudas y bonificaciones para proyectos empresariales llevados a cabo por discapacitados; admitir que los empresarios cumplan las cuotas de contratación de minusválidos contratando a autónomos; establecer bonificaciones en Seguridad Social o tributarias para ellos y otras análogas, pues, de lo contrario, la prohibición de discriminación resulta muy difícil de cumplir ${ }^{23}$.

Al mismo tiempo deben fomentarse acciones positivas hacia estos trabajadores autónomos discapacitados que consistirán en apoyos de carácter específico destinados a prevenir o compensar las desventajas o especiales dificultades que tienen en la incorporación y participación plena en los distintos ámbitos de la vida, atendiendo a los diferentes grados y tipos de discapacidad. Tales medidas de acción positiva pueden consistir en apoyos complementarios (ayudas económicas y técnicas,

22 Ampliamente sobre el particular, M.D. García Valverde (2003) "El trabajo y la protección social de las personas con discapacidad", Revista Electrónica de Geriatría y Gerontología, 2, Vol. 5, p. 10 ó F.J. Prados de Reyes y M.T. Alameda Castillo (2006) "Relaciones de trabajo y política de empleo de los trabajadores con discapacidad". Régimen jurídico de las personas con discapacidad en España y en la Unión Europea. Granada: Comares, pp. 295-356.

23 E. González Biedma (2007) "Derechos y deberes de los trabajadores autónomos". S. del Rey Guanter (dir.) Comentarios al Estatuto del Trabajo Autónomo, ed. cit., pp. 119-120. 
asistencia personal, servicios especializados y ayudas y servicios auxiliares para la comunicación) y normas, criterios y prácticas más favorables.

De forma muy genérica la Ley 51/2003 orienta sobre los derechos que en esta materia tienen los autónomos y cuándo van a poder ser acreedores de la mencionada protección. En primer lugar, cabe entender por discapacitados a quienes se les haya reconocido un grado de minusvalía igual o superior al 33 por ciento, considerando, en todo caso, afectados por una igual o superior al 33 por ciento a los pensionistas de la Seguridad Social que tengan reconocida una pensión de incapacidad permanente en el grado de total, absoluta o gran invalidez ex Real Decreto 1414/2006, de 1 de diciembre. Las disposiciones generales de la Ley se detienen en la definición de una serie de conceptos cuya explicación resulta imprescindible para garantizar una adecuada interpretación de la misma y salvaguardar el principio de seguridad jurídica, en este caso, de los trabajadores autónomos. Y así, se considera vulnerado el derecho a la igualdad de oportunidades de los autónomos con discapacidad cuando se produzcan discriminaciones directas o indirectas, acosos, incumplimientos de las exigencias de accesibilidad y de realizar ajustes razonables, así como el incumplimiento de las medidas de acción positiva legalmente establecidas. Cuando esta vulneración se produzca resultará necesario el establecimiento de una serie de medidas contra la discriminación que tengan como finalidad prevenir o corregir que un trabajador autónomo con discapacidad sea tratado de una manera directa o indirecta menos favorablemente que otro trabajador que no lo sea, en una situación análoga o comparable.

Con independencia del sometimiento a un procedimiento de arbitraje en las situaciones en que se aprecie discriminación, el trabajador autónomo tendrá derecho a la tutela judicial del derecho de la igualdad de oportunidades de las personas con discapacidad que comprenderá la adopción de todas las medidas necesarias para poner fin a la violación del derecho y prevenir violaciones ulteriores, así como para restablecer al perjudicado en el ejercicio pleno de su derecho. Junto a lo anterior se prevé la reparación o indemnización a que pueda dar lugar la reclamación correspondiente, que no estará limitada por un tope máximo fijado $a$ priori. Además, el autónomo tendrá derecho a la indemnización por daño moral aun cuando no existan perjuicios de carácter económico, el cual se valorará atendiendo a las circunstancias de la infracción y a la gravedad de la lesión. 
El principio de igualdad y la no discriminación del trabajador autónomo en el ordenamiento jurídico español

Por último, como colofón a este reconocimiento del derecho de defensa del trabajador autónomo discriminado por razones de discapacidad, la Ley $51 / 2003$, de 3 de diciembre encomienda la adopción de las medidas necesarias para proteger a las personas físicas o jurídicas contra cualquier trato adverso o consecuencia negativa que pueda producirse como reacción ante una reclamación o ante un procedimiento destinado a exigir el cumplimiento del principio de igualdad de oportunidades $^{24}$.

No se puede, por lo tanto, evitar contratar servicios a un autónomo por su religión o por su orientación sexual, y tampoco por su lengua o edad, prohibición que se extiende explícitamente a las Administraciones públicas. Si se pretende que el amplio colectivo de discapacitados - que parten de una situación de desventaja frente a aquellos que no padecen una reducción significativa de sus facultades físicas o psíquicas - pueda desarrollarse en sociedad en plano de igualdad, es necesario facilitarle el acceso al empleo, única fuente de ingresos para la inmensa mayoría de la población y, por ende, elemento imprescindible para toda integración social ${ }^{25}$. Es decir, el empleo de las personas con discapacidad no constituye una "prestación social" sino el ejercicio de un derecho constitucional que los poderes públicos han de facilitar y tutelar.

\section{GARANTÍAS DE EFECTIVIDAD DE LA TUTELA CONTRA LOS ACTOS DISCRIMINATORIOS \\ El Estatuto del Trabajo Autónomo, como no podía ser de} otra manera, no olvida el plano de las garantías de efectividad de la tutela contra los actos discriminatorios, de ahí que además de la sanción de nulidad prevea una tutela judicial reforzada en términos análogos a los que ya disfrutan los trabajadores subordinados $\mathrm{y}$, en general, todos los ciudadanos. En concreto, ex art. 6.3 LETA, el trabajador autónomo -por sí o a través de las asociaciones que lo representan- que considere lesionados sus derechos fundamentales o se vea afectado por un trato discriminatorio

ed. cit., p. 81

24 F.A. González Díaz (2007) "Régimen profesional del Trabajador Autónomo",

25 C. Jernaro Río (2004) "Trabajo y discapacidad". J. de Elena y Peña (ed.) Desigualdad social y relaciones de trabajo. Salamanca: Ediciones Universidad de Salamanca, p. 132. 
podrá recabar la tutela del derecho ante el orden jurisdiccional competente por razón de la materia, a través de un procedimiento sumario y preferente. En el caso de vulneración de derechos del TRADE, dicho orden no puede ser otro que el social, pues a tal jurisdicción se encomiendan los litigios planteados por los mismos en cuanto a su ejercicio profesional. En el caso de los autónomos ordinarios habrá que acudir a la vía general de tutela de los derechos fundamentales y libertades públicas (arts. 11 y ss. de la Ley 62/1978, de 26 de diciembre, sobre Protección Jurisdiccional de los Derechos Fundamentales de la Persona), siendo competentes los Juzgados de Primera Instancia.

Resulta obvia la expresa alusión que aquí se hace al derecho a la tutela judicial reconocido en el art. 24 de la CE, el cual, obviamente, no debe encontrar restricción alguna a la hora de aplicarse a los trabajadores autónomos. Como consecuencia práctica del recordatorio de este derecho debe aludirse a los derechos a su vez derivados de él $y$, particularmente, a la faceta del derecho conocida como "indemnidad". Un autónomo, por lo tanto, no podrá ser discriminado por haber efectuado una reclamación judicial.

Si el órgano judicial estimara probada la vulneración del derecho denunciado, declarará la nulidad "radical" de la conducta, decretará el cese inmediato de la misma y la reposición de la situación al momento anterior a producirse, así como la reparación de las consecuencias derivadas del acto, incluida la indemnización procedente. Ciertamente, la equiparación con lo dispuesto en los arts. 180 y 181 de la Ley de Procedimiento Laboral (LPL) es evidente, salvo la omisión de referencia alguna a las reglas sobre inversión de la carga de la prueba que, dada su importancia, quizás debiera también haber incorporado la LETA de modo específico. Por último, contempla también una garantía de integración judicial del contenido del contrato por nulidad de la cláusula discriminatoria o anticonstitucionalidad que responde a una regla de principio del Derecho Privado cuando están en juego intereses sociales primarios como ocurre en materia de consumo ${ }^{26}$ :

las cláusulas contractuales que vulneren el derecho a la no discriminación o cualquier derecho fundamental serán nulas y se tendrán por no puestas. El juez que declare la

26 C. Molina Navarrete (2007) "Trabajadores en la frontera: Comentarios al Estatuto del Trabajo Autónomo", ed. cit., pp. 88-89. 
invalidez de dichas cláusulas integrará el contrato con arreglo a lo dispuesto en el art. 1258 del Código Civil y, en su caso, determinará la indemnización correspondiente por los perjuicios sufridos,

pues en todos aquellos casos en que se haya acreditado la lesión de un derecho fundamental, existen bases suficientes para fijar en vía judicial la indemnización ${ }^{27}$. El mencionado artículo establece unos criterios genéricos sobre la perfección de los contratos indicando que, desde ella, obligan "... no sólo al cumplimiento de lo expresamente pactado, sino también a todas las consecuencias que, según su naturaleza, sean conformes a la buena fe, al uso y a la ley".

\section{BIBLIOGRAFÍA}

BARRIOS BAUdor, G. y M. APILLUELo MARTín (2007) Introducción al Estatuto del Trabajo Autónomo. Cizur Menor: Thomson-Aranzadi.

CACHÓn RodRíGueZ, L. Dir. (2004) Colectivos desfavorecidos en el mercado de trabajo y políticas activas de empleo. Madrid: MTAS.

CANAls SANS, G. (2003) "La inserción de personas con discapacidad en la empresa ordinaria", Documentación Social, 130, pp. 229-248.

DURÁN I LLEIDA, J.A. (2005) "La debida protección de los autónomos, una necesidad urgente", Revista de economía pública, social y cooperativa, 52, pp. 23-28.

ESCRIBANO GUTIÉRREZ, J. (2008) "Igualdad y acceso al empleo de las personas con discapacidad", Revista Española de Derecho del Trabajo, 138, pp. 377-406.

FERNÁNDEZ-COSTALES MUÑIZ, J. (2008) "Aproximación de la figura del trabajador autónomo y su régimen profesional común en la Ley 20/2007, de 11 de julio, del Estatuto del trabajo autónomo", Revista Técnico Laboral, 115, pp. 75-87.

27 STCo 247/2006, de 24 de julio, a diferencia de lo que hasta el momento había entendido la jurisprudencia social, entre otras, STS 21 julio 2003 (RJ 6941). 
García MURCiA, J. (2007) "Trabajo autónomo". J. García MuRCia (dir.) El trabajo autónomo y otras formas de trabajo no asalariado. Cizur Menor: Thomson-Aranzadi, pp. 21-25.

García VAlVERDE, M.D. (2003) "El trabajo y la protección social de las personas con discapacidad", Revista Electrónica de Geriatría y Gerontología, núm. 2, Vol. 5, pp. 10-15.

Gómez ABELLEIRA, F. (2006) "Trabajadores autónomos y seguridad y salud en el trabajo: una perspectiva de Derecho Comparado", Alcor de MGO, 7, pp. 89-119.

González BiEDMA, E. (2007) "Derechos y deberes de los trabajadores autónomos". S. del REY GUANTER (dir.) Comentarios al Estatuto del Trabajo Autónomo. Valladolid: Lex Nova, pp. 115-138.

GonZÁlEz DíAZ, F.A. (2007) "Régimen profesional del trabajador autónomo". J. LuJÁn AlCARAZ (dir.) El Estatuto del Trabajo Autónomo. Análisis de la ley 20/2007, de 11 de julio. Murcia: Laborum, pp. 69-96.

Colectivo IOE (C. Pereda, M.Á. De Prada y W. ACtIS) (2003) La inserción laboral de las personas con discapacidades. Barcelona: Fundación La Caixa.

Jernaro Río, C. (2004) "Trabajo y discapacidad". J. de Elena y PeÑa (ed.) Desigualdad social y relaciones de trabajo. Salamanca: Ediciones Universidad de Salamanca, pp. 129-142.

MARTínez BARRoso, M.R. (2007) Riesgo psicosocial en el sistema de protección social. Murcia: Laborum.

- (2007) "La responsabilidad del trabajador autónomo en materia de prevención de riesgos laborales", Revista Técnico Laboral, 114, pp. 725-740.

- y S. RodRíGUez ESCANCIANO (2004) El espacio profesional del Graduado Social y del licenciado en Ciencias del Trabajo. León: Universidad de León.

Molina NAVARRETE, C. (2007) "Trabajadores en la frontera: Comentarios al Estatuto del Trabajo Autónomo", Revista de Trabajo y Seguridad Social, 295, pp. 43-142.

MONTOYA Melgar, A. y R. MARTín JimÉnez (2007) Estatuto del Trabajo autónomo. Comentario a la Ley 20/2007, de 11 de julio. Madrid: Thomson-Civitas.

PALOMEQUe LóPEZ, M.C. (2007) "El derecho de los trabajadores autónomos a la seguridad y salud en su trabajo", Revista de Derecho Social, 40, pp. 9-30. 
Prados de Reyes, F.J. y M.T. Alameda Castillo (2006) "Relaciones de trabajo y política de empleo de los trabajadores con discapacidad". E. ALCAín MARTínEZ, J. GONZÁlEZ-BADÍA FRAGA y C. MOLINA FERNÁNDEZ (coords.) Régimen jurídico de las personas con discapacidad en España y en la Unión Europea. Granada: Comares, pp. 295-356.

REY GUANTER, S. del (2007) "Introducción: trascendencia, función y características esenciales de la LETA". S. del REY GUANTER (dir.) Comentarios al Estatuto del Trabajo Autónomo. Valladolid: Lex Nova, pp. 25-38.

RodríGuez-PIÑERo Y BRAVo-FerRer, M. y M.E. CASAS BAAMONDE (2000) "El trabajo autónomo y el Derecho del Trabajo", Relaciones Laborales, 1, pp. 73-90.

RuIz CASTILLO, M.M. (1991) "Delimitación subjetiva del Derecho del Trabajo. Un interrogante específico: el trabajo parasubordinado", Relaciones Laborales, 15/16, pp. 135-188.

Segoviano AstabuRuaga, M.L. (2007) "Trabajadores autónomos económicamente dependientes", Documentación Laboral, 81, pp. 29-46.

Sempere NAVARRo, A.V. et al. (2001) Derecho de la seguridad y salud en el trabajo, $3^{\mathrm{a}}$ ed. Madrid: Civitas.

SIRVENT HERNÁNDEZ, N. (2007) "Los acuerdos de interés profesional como fuente reguladora de la relación profesional de los trabajadores autónomos económicamente dependientes", Revista de Trabajo y Seguridad Social, 296, pp. 49-66.

UPTA (2005) "Posición de la UPTA sobre el Estatuto del Trabajo Autónomo", Documentación Laboral, 73, pp. 133-143.

VALDÉS DAL-RE, F. (2007) "Un Estatuto para el trabajo autónomo", Documentación Laboral, 81, pp. 9-27. 